\title{
O OBJETO ANAFÓRICO NO PORTUGUÊS DE FLORIANÓPOLIS: UMA ANÁLISE DIACRÔNICA ${ }^{1}$
}

\author{
THE ANAPHORIC OBJECT IN THE PORTUGUESE OF FLORIANÓPOLIS: \\ A DIACHRONIC ANALYSIS
}

Sueli Costa

Professora do Instituto Federal de Santa Catarina (IFSC)

sueli.costa@ifsc.edu.br

\begin{abstract}
RESUMO: Esta pesquisa trata da investigação diacrônica em torno da (não)realização do objeto anafórico no português de Florianópolis. Investigamos esse fenômeno considerando o século XIX e o século XX, tomando como corpus peças teatrais de autores nascidos em Florianópolis. O suporte teórico que embasa a pesquisa está pautado na teoria de variação e mudança linguística (WEINREICH, LABOV e HERZOG, 1968; LABOV, 1972; 1978; 1982; 1994) e na teoria de Kroch $(1978,1989,1994,2001)$ sobre a propagação da mudança e as gramáticas em competição. Considerando apenas os contextos com verbos transitivos em que ocorrem objetos anafóricos, observamos se há mudança e, em caso positivo, de que maneira ela ocorre. O corpus é composto por quatorze peças teatrais cujos autores nasceram nos séculos XIX e XX e de onde se extraíram os dados que foram submetidos ao programa estatístico VARBRUL (PINTZUK, 1988) para que se processasse a análise. Após a análise dos resultados, observou-se que, no português de Florianópolis houve expressivo aumento na ocorrência de objetos nulos com antecedentes SNs, do século XIX para o século XX. Além disso, os resultados sugerem, nos termos de Kroch, a existência de gramáticas em competição nessa variedade do português: uma de objetos nulos e outra de objetos preenchidos.
\end{abstract}

PALAVRAS-CHAVE: Objeto nulo. Variação e mudança linguística. Gramáticas em competição.

ABSTRACT: This work presents a diachronic investigation of the anaphoric object in the Portuguese spoken in Florianópolis. It investigates how it occurs in both the $19^{\text {th }}$ and $20^{\text {th }}$ centuries based on Linguistic Variation and Change Theory (WEINREICH, LABOV e HERZOG, 1968; LABOV, 1972; 1978; 1982; 1994) as well as Grammatical Competition Theory (KROCH 1978, 1989, 1994, 2001). The research deals with transitive verb contexts in which anaphoric objects are present to investigate if linguistic change occurs and, if so, how it happens in Florianópolis' Portuguese. The study involves fourteen dramatic texts whose authors were born in Florianópolis to investigate if there is any change in the way anaphoric objects appear (or not). It will be possible to know which contexts allow null objects on the Portuguese spoken in Florianópolis after submitting data to VARBRUL statistic program (PINTZUK S., 1988) to process the analysis. The study will show that, specially in the $20^{\text {th }}$ Century, noun phrases originate more frequently objects as empty categories. Moreorever, results suggest, according to Kroch's theory, that there is grammatical competition in the Portuguese spoken in Florianópolis, based on data with full or null objects.

KEYWORDS: Null object. Linguistic variation and change. Grammatical competition.

\footnotetext{
${ }^{1}$ Este artigo discute parte dos resultados apresentados em minha tese de Doutorado, defendida em 2010, na Universidade Federal de Santa Catarina, sob a orientação da Profa. Dra. Izete Lehmkuhl Coelho.
} 


\section{INTRODUÇÃO}

Dentre os muitos fenômenos que estão em variação na língua portuguesa (preenchimento do sujeito, ordem do sujeito, concordância, entre outros), encontram-se os objetos anafóricos, que ora se apresentam de maneira explícita e ora são omitidos nos mais diferentes contextos.

No dia a dia, é possível notar que o uso dos pronomes complementos clíticos vem sendo diferenciado em relação ao que é normalmente estudado nas gramáticas tradicionais. Percebe-se que, no cotidiano, os clíticos de terceira pessoa (o, a, os, as) quase já não aparecem, sendo substituídos por um sintagma nominal, pelo pronome sujeito correspondente (uso muitas vezes estigmatizado) ou ainda, simplesmente, pelo apagamento do objeto direto, como ocorre no exemplo a seguir:

(1) - Você viu aquela moto na vitrine da loja? Tive vontade de comprar aquela máquina!

- E por que você não $a$ compra? As facilidades de pagamento são muitas...

- É... acho que vou comprar cv ...

Os fenômenos em variação na língua portuguesa dizem respeito tanto a questões léxicosemânticas, fonológicas, morfológicas, morfossintáticas e discursivas quanto sintáticas, e é justamente no âmbito da sintaxe que se situa o fenômeno que foi objeto desta pesquisa: o(não) preenchimento do objeto anafórico no português de Florianópolis. Nosso intuito é rastrear a (não)realização do objeto direto em peças teatrais dos séculos XIX e XX, escritas por autores florianopolitanos para, depois, comparar os resultados obtidos com os de outros trabalhos já desenvolvidos com base nos dados de outras localidades.

Alicerçados nos estudos desenvolvidos por Labov $(1972 ; 1978 ; 1982 ; 1994)$ acerca da variação e da mudança linguística é que investigamos o fenômeno a fim de observar os resultados de pesquisas que levaram em conta outras amostras - tanto sincrônicas quanto diacrônicas - , confrontá-los com os resultados desses trabalhos e, então, confirmar - ou não - a tendência ao apagamento do objeto anafórico no português de Florianópolis.

Considerando, ainda, a proposta de existência de gramáticas em competição de Kroch (1978; 1989; 1994; 2001), analisaremos os resultados com o objetivo de investigar se estamos diante de um caso de competição entre gramáticas no que diz respeito ao preenchimento do objeto. Sete questões nortearam nossa pesquisa:

(i) Os resultados desta pesquisa com peças teatrais de autores de Santa Catarina atestam outros resultados com corpora de outros estados brasileiros em relação à tendência ao apagamento do objeto pronominal?

(ii) Há indicativo de mudança em progresso?

(iii) Em caso afirmativo, como a mudança se encaixa no sistema?

(iv) Quais os fenômenos linguísticos que estão associados à (não) realização do objeto? Em que medida o ano de estreia da peça teatral - fenômeno extralinguístico - está associado à (não)realização do objeto em Florianópolis?

(v) Os grupos de fatores que condicionam o apagamento do objeto são os mesmos em cada século?

(vi) Há uma situação de gramáticas em competição (Cf. KROCH 1989, 1994, 2001) na amostra em 
estudo?

Ao tentarmos responder aos questionamentos a respeito da língua, logo percebemos que esta não é uma tarefa simples. Por mais que muitos estudiosos já tenham proposto definições e explicações para nosso objeto de estudo, suas conclusões continuam sendo alvo de reflexão e de crítica. Isso ocorre porque, em primeiro lugar, a língua é viva e mutante e, como tal, não pode ser pacificamente enquadrada em determinadas teorias. Em segundo lugar, a maioria de nós, falantes da língua, vem de um sistema de ensino que buscava classificar palavras, nomear termos e "obrigar" todos nós a fazermos uso da tal língua que a gramática tenta refletir e que aprendemos (?) na escola. ${ }^{2}$

Muitos trabalhos já foram elaborados sobre o assunto e, com certeza, o que há de mais inovador em nossa pesquisa é o corpus utilizado. A maioria dos trabalhos desenvolvidos tem por base dados de regiões brasileiras diferentes do Sul (Florianópolis, mais especificamente). Em nossa pesquisa, além de concentrarmos dados do português em obras de autores cuja origem é o sul do Brasil - o que já é uma inovação -, é preciso considerar, também, que a região da cidade de Florianópolis foi colonizada basicamente por imigrantes portugueses (açorianos), o que deve possivelmente fazer com que traços linguísticos lusitanos dos séculos XIX e XX possam estar registrados no modo de falar das personagens apresentadas nas peças.

O corpus que analisamos também nos permitiu, nas palavras de Labov (1994), fazer "o melhor uso dos maus dados" de que dispúnhamos. Nossa escolha por trabalhar com peças teatrais não foi por acaso; buscávamos dados que representassem o máximo possível da fala das pessoas dos dois séculos investigados. Assim, o texto teatral tornou-se a melhor opção, uma vez que, em se tratando de estudo diacrônico, não poderíamos dispor de gravações para a coleta dos dados.

\section{PROBLEMATIZAÇÃO}

Ainda que muitas vezes adotem diferentes perspectivas em suas abordagens, vários gramáticos da língua portuguesa (BECHARA, 1974; CEGALLA, 1984; MACAMBIRA, 1987; PERINI, 1995; CUNHA e CINTRA, 1996; entre outros) reconhecem que a classificação do verbo quanto à transitividade depende do contexto em que é empregado. Há casos em que um verbo tradicionalmente reconhecido como transitivo é empregado com diferentes transitividades, como ocorre nos exemplos a seguir (BECHARA, p. 205):

(2) Ele passou a presidente. (verbo de ligação)--> "assumiu o cargo de"

(3) O caçula passou o mais velho. (verbo transitivo direto) -> "ultrapassou em altura"

(4) A chuva passou. (verbo intransitivo)--> "cessou"

(5) Maria passou as novidades às colegas. (verbo transitivo direto e indireto) --> "contou"

A transitividade do verbo está associada ao contexto em que ele se insere e, portanto, ao uso ou não do objeto a ele relacionado. Assim, apesar de muitas vezes apresentarem a classificação tradicional dos verbos (transitivo, intransitivo), os gramáticos acabam por se convencer de que o ato de classificar os elementos, no caso o verbo, que compõem uma língua passa, obrigatoriamente, pelo estudo do uso dessa língua.

Assim, torna-se possível afirmar que o estudo da transitividade verbal vai além da mera classificação dos verbos; é necessário que se analise o contexto em que é utilizado para, depois, tentar classificá-lo.

\footnotetext{
${ }^{2}$ Ver MATTOS E SILVA, 1989.
} 
O fato de alguns gramáticos normativos reconhecerem a importância de considerarmos o contexto de uso dos verbos para só então reconhecer sua transitividade confirma o que se observa, na prática, em algumas situações. Muitas vezes o falante utiliza o complemento verbal em determinada situação e, em outra, com o mesmo verbo, opta pelo apagamento do objeto, quando a referência é clara para o interlocutor. É justamente neste ponto que se concentrou o alvo de nossa pesquisa, que buscou investigar em que medida ocorre a opção pelo preenchimento ou elipse do complemento verbal no português de Florianópolis dos séculos XIX e XX.

Cegalla (1984), Faraco e Moura (1987), Cunha e Cintra (1996) e Paschoalin e Spadoto (1996), entre outros, são unânimes ao explicarem que os complementos verbais são complementos do verbo, uma vez que há verbos cujo sentido está incompleto na oração. São, portanto, indispensáveis para o entendimento da sentença. Por outro lado, os autores alertam para o fato de que se deve prestar atenção ao contexto, ou seja, ao emprego do verbo na frase. É esse que vai indicar qual a transitividade do verbo no momento em que está sendo utilizado, uma vez que o verbo pode assumir diferentes sentidos.

Ainda sobre os complementos verbais, não podemos deixar de mencionar Raposo (2004), segundo o qual, o português, tanto o brasileiro quanto o europeu, tem como uma de suas características mais peculiares a possibilidade de "objetos nulos semanticamente definidos" (p. 42).

$\mathrm{O}$ autor lembra, ainda, que houve uma gama de estudos envolvendo os condicionamentos sintáticos, semânticos, pragmáticos e sociolinguísticos que cercam o objeto nulo no Brasil dos anos 1970 e 1980. Raposo dá destaque aos trabalhos desenvolvidos por Omena (1978), Pereira (1981), Kato e Tarallo (1987) e Duarte (1986) acerca do objeto nulo.

Raposo explica que, apesar de serem as duas únicas variedades a permitirem o objeto nulo praticamente nos mesmos contextos, os fatores que as levam a isso são diferentes: no português europeu, o objeto anafórico nulo resulta da elipse de um clítico, de um sintagma nominal (SN) ou de uma oração; já no português brasileiro, é gerado a partir da omissão de um pronome oblíquo ou pleno.

\section{ALGUNS ESTUDOS SOBRE A (NÃO) REALIZAÇÃO DO OBJETO}

Para discutirmos questões que envolvem a variação/mudança na língua considerando nosso objeto de estudo, retomaremos nesta seção algumas pesquisas realizadas acerca do preenchimento do objeto para que sirvam de ponto de partida para a análise que desenvolveremos mais adiante.

Omena (1978) analisou o português falado no Rio de Janeiro e não encontrou nenhuma ocorrência de pronome clítico acusativo em seus dados. Levando-se em conta que seus quatro informantes tinham baixa escolaridade (estavam frequentando o programa de educação de adultos), a autora levanta a hipótese de que o uso dos clíticos acusativos talvez esteja relacionado à escolarização3. Os resultados de Omena são apresentados a seguir:

\footnotetext{
${ }^{3}$ Essa hipótese foi mais tarde confirmada por Duarte (1986), no estudo sobre os clíticos que realizou com informantes de São Paulo, em que controlou o nível de escolarização dos indivíduos.
} 


\begin{tabular}{lcccl}
\hline & $\mathbf{1}^{\circ}$. inf. & $\mathbf{2}^{\circ}$ Inf. & $\mathbf{3}^{\circ}$ Inf. & $\mathbf{4}^{\circ}$ Inf. \\
\hline Pronome Pleno & 128 & 67 & 88 & 63 \\
\hline Categoria Vazia & 331 & 307 & 284 & 147 \\
\hline TOTAL & 459 & 374 & 372 & 210 \\
\hline \% de categoria vazia & 72,1 & 82,1 & 76,3 & 70 \\
\hline
\end{tabular}

Tabela 01: Número de ocorrências de pronomes plenos e categorias vazias por informante, segundo Omena (1978)

Tarallo (1983) também já apontava para o fenômeno da queda dos clíticos na língua portuguesa, como se pode observar na tabela a seguir que mostra, diacronicamente, o percentual de retenção do objeto direto anafórico:

\begin{tabular}{cc}
\hline I. $1^{\text {a }}$ metade do século XVIII & $89.2 \%$ \\
\hline II. $2^{\text {a }}$ metade do século XVIII & $96,2 \%$ \\
\hline III. $1^{\text {a }}$ metade do século XIX & $83,7 \%$ \\
\hline IV. $2^{\text {a }}$ metade do século XIX & $60,2 \%$ \\
\hline V. Corpus sincrônico (1981) & $18,0 \%$ \\
\hline
\end{tabular}

Tabela 02 : Frequência de retenção do objeto direto anafórico em cinco momentos históricos (extraída de TARALLO, 1983, p.166-193, apud CYRINO, 1993, p. 173)

Além desses, Duarte (1986) mostrou que também na fala de paulistanos e na linguagem utilizada na TV o percentual de uso da categoria vazia objeto é mais alto que o de uso de clíticos, pronomes lexicais e SNs anafóricos. Em estudo realizado a partir de dados de fala de paulistanos nativos e de gravações da linguagem utilizada na TV, Duarte (1986) analisou o preenchimento do objeto a partir do uso de clítico acusativo, pronome lexical e categoria vazia levando em conta dois fatores sociais: escolaridade e faixa etária. Após o cômputo dos dados, a autora obteve os seguintes percentuais:

\begin{tabular}{lcc}
\hline Variante & Ocorrências & \% \\
\hline Clítico & 97 & 4,9 \\
\hline Pronome Lexical & 304 & 15,4 \\
\hline$[$ SNe] & 1235 & 62,6 \\
\hline SNs anafóricos & 338 & 17,1 \\
\hline TOTAL & 1974 & 100
\end{tabular}

Tabela 03: Distribuição dos dados computados segundo a variante usada (DUARTE [1986] 1989, p. 21)

Com relação aos fatores sociais, Duarte afirma ter chamado sua atenção a ausência de 
clíticos na fala dos jovens (15 a 17 anos). Por outro lado, nos outros grupos - de 22 a 33, de 34 a 46 e acima de 46 anos - o uso dos clíticos se revelou invariável com relação à faixa etária, mas aumentou de acordo com o nível de escolaridade. Já o uso do pronome lexical, mais frequente na fala dos jovens $(23,5 \%)$, é cada vez menos percebido à medida que sobem a escolaridade e a faixa etária.

Quanto ao uso de SNs anafóricos, os resultados da autora mostraram que seu percentual de uso é maior que o do pronome lexical, quando se trata de informantes mais velhos e com nível mais alto de escolaridade.

A autora ainda observa que em todos os grupos de informantes há favorecimento do uso da categoria vazia de objeto, sinalizando um estágio de implementação dessa variante no sistema linguístico. Para a autora, a ocorrência da categoria vazia em textos de grande circulação (revistas, jornais, literatura, traduções) "distingue o português do Brasil das línguas irmãs, exigindo uma análise que leve em conta o discurso" (DUARTE, op. cit., p. 32)

Em estudo realizado em 1990, Cyrino obteve resultados que apontaram para uma mudança diacrônica no português brasileiro. Segundo ela, os percentuais mostraram um aumento no uso de objetos nulos que eram, nas primeiras épocas, restritos a alguns contextos, mas que mais tarde surgiram mais livremente. Seguem os percentuais de ocorrência de objetos nulos em relação ao tempo:

\begin{tabular}{cc}
\hline Século & Objetos Nulos $(\%)$ \\
\hline $1^{\text {a }}$ metade do séc. XVIII & 4,2 \\
\hline $1^{\text {a }}$ metade do séc. XIX & 41,6 \\
\hline $2^{\text {a }}$ metade do séc. XIX & 23,2 \\
\hline $1^{\text {a }}$ metade do séc. XX & 69,5 \\
\hline $2^{\text {a }}$ metade do séc. XX & 81,1 \\
\hline
\end{tabular}

Tabela 04: Objetos nulos no tempo (adaptada de CYRINO, 1990)

Em outro estudo diacrônico, Kato, Cyrino e Correa (1995) defendem a ideia de que o objeto nulo no Português do Brasil (PB) é um clítico nulo. As autoras analisaram diacronicamente o fenômeno do objeto nulo em textos da primeira metade do século XVI até o século XX. Ao compararem os resultados do estudo diacrônico com a "aquisição" dos clíticos de terceira pessoa ao longo do período de escolarização, perceberam que o percentual de uso dos clíticos por estudantes universitários (14\%) era semelhante ao percentual encontrado em dados de peças teatrais do século XX (11,2\%). Além dessa constatação, lembram ainda que o português brasileiro tem sido reconhecido como uma língua que licencia o uso de pronomes fortes (ele(s), ela(s)), ou seja, pronomes lexicais de terceira pessoa em posição de objeto ${ }^{4}$ apesar de essa prática ser condenada pelas pessoas mais instruídas, que preferem usar institucionalmente certos "fósseis da linguagem".

Em um outro momento, Cyrino (2001) realizou estudo sobre o objeto a partir de anúncios de revistas brasileiras e portuguesas, destinadas ao público adulto, cujos resultados são apresentados na tabela a seguir:

\footnotetext{
${ }^{4}$ De acordo com resultados obtidos por Cyrino (1993), houve um aumento no percentual de ocorrência de objeto nulo em 1838-1844, que era de 0,5, para 44, em 1973
} 


\begin{tabular}{|c|c|c|c|c|c|c|}
\hline & \multicolumn{2}{|c|}{ Objeto Nulo } & \multicolumn{2}{|c|}{ Objeto Preenchido } & \multicolumn{2}{|c|}{ TOTAL } \\
\hline & $\mathbf{N}^{\mathbf{o}}$ & $\%$ & $\mathbf{N}^{\mathbf{o}}$ & $\%$ & $\mathbf{N}^{\mathbf{o}}$ & $\%$ \\
\hline PB & 19 & 76 & 6 & 24 & 25 & 100 \\
\hline PE & 1 & 3 & 33 & 97 & 34 & 100 \\
\hline
\end{tabular}

Tabela 05: Objeto nulo vs. objeto preenchido no PB e no PE (adaptada de CYRINO 2001, p. 176 ) autora foi

A única ocorrência de objeto nulo encontrada nos dados de Português Europeu (PE) pela

(6) "Preencha os seus dados, cole o cupão num postal dos CTT e envie

QUO/NIVEA FOR MEN, Rua Filipe Folque 40 - 2 , 1069-124 Lisboa." para a promoção

Cyrino concluiu esse trabalho afirmando que, para ela, o objeto nulo do PB "é reconstrução", ou seja, o mesmo processo de elipse de VP, para o qual, segundo a autora, algumas propostas (LOBECK, 1987; CHAO, 1987; ZAGONA, 1982 e MATOS, 1992) mencionam a necessidade de um licenciador. Lembra, ainda, que, em 1999, ela mesma propôs a necessidade de haver uma categoria funcional para c-comandar a estrutura em questão. Ao contrário do que ocorre no $\mathrm{PB}, \mathrm{o} \mathrm{PE}$ não teria esse objeto nulo porque não tem como licenciá-lo e então, segundo ela, a elipse de VP seria diferente no PB e no PE.

Outra análise diacrônica realizada por Cyrino (1997) sobre o preenchimento do objeto no PB levando em consideração dados de textos de peças teatrais escritas em PB e PE também mostrou alguns resultados interessantes para este estudo. Dentre eles, chamam-nos atenção aqueles referentes à análise quantitativa que mostram um decréscimo no número de objetos preenchidos, conforme mostra a tabela a seguir:

\begin{tabular}{ccccccc}
\hline \multirow{2}{*}{ SÉCULO } & \multicolumn{2}{c}{ NULAS } & \multicolumn{2}{c}{ PREENCHIDAS } & \multicolumn{2}{c}{ TOTAL } \\
& $\mathbf{N}^{\mathbf{0}}$ & $\mathbf{\%}$ & $\mathbf{N}^{\mathbf{0}}$ & $\mathbf{\%}$ & $\mathbf{N}^{\mathbf{0}}$ & $\boldsymbol{\%}$ \\
\hline XVI & 31 & 10,7 & 259 & 89,3 & 290 & 100 \\
\hline XVII & 37 & 12,6 & 256 & 87,4 & 293 & 100 \\
\hline XVIII & 53 & 18,5 & 234 & 81,5 & 287 & 100 \\
\hline XIX & 122 & 45,0 & 149 & 55,0 & 271 & 100 \\
\hline XX & 193 & 79,1 & 51 & 20,9 & 244 & 100 \\
\hline
\end{tabular}

Tabela 06: Distribuição de posições de objetos nulas vs. preenchidas (adaptada de CYRINO, 1997, p. 246)

Os trabalhos de Cyrino (1993, 1997, 2003) têm apontado para uma tendência, no PB, à ocorrência de objetos nulos, ao contrário do que ela constatou para o PE, que dá preferência ao preenchimento do objeto. A autora também defende que os objetos nulos encontrados no PB são, na realidade, clíticos de terceira pessoa nulos, uma vez que somente quando há na sentença 
referencialidade "suficiente" para recuperar o significado, será possível omitir o objeto (na verdade, o clítico).

Além desses estudos, Cyrino (2007) também discute o objeto nulo em um corpus constituído de cartas de leitores e redatores de jornais de diversos estados brasileiros.

Nesse estudo, além de a autora apresentar os resultados que obteve com a pesquisa, ela também retoma conceitos como o da hierarquia da referencialidade, segundo a qual a referencialidade é "altamente relevante para a pronominalização em várias línguas." (p. 288). De acordo com essa hierarquia, os argumentos $[+\mathrm{N},+$ humano] estão na posição mais alta, enquanto que a posição mais baixa é ocupada pelos não argumentos. Em se tratando de pronomes, a posição mais alta na hierarquia é ocupada pela primeira e segunda pessoas, uma vez que são inerentemente humanos. Já a terceira pessoa estaria na posição mais baixa, pois se refere a uma proposição (o "neutro") e detém o traço [- humano]. Todos esses traços interagem, ainda, com os traços [-/+ específico].

Dessa forma, quando há opção interna para categorias vazias ou preenchidas em determinada língua, a escolha é influenciada pelo estatuto referencial do antecedente.

\section{CORPUS E METODOLOGIA}

Como o estudo que nos propusemos a realizar é de cunho diacrônico, a primeira dificuldade para não dizer, impossibilidade - que enfrentamos foi a de conseguir entrevistas com informantes para compor o corpus da pesquisa. Por essa razão, optamos por estudar peças teatrais.

O banco diacrônico que forneceu dados para o estudo que realizamos acerca dos padrões de variação e mudança na realização do objeto no português florianopolitano é constituído de quatorze peças teatrais, cujas datas de estreia/publicação estão distribuídas entre 1867 e 1996 e de onde se extraíram 614 dados (358 do século XIX e 256 do século XX).

Os textos teatrais analisados fazem parte de um projeto, ainda em curso, que diz respeito à diacronia do português em Santa Catarina ${ }^{5}$, vinculado ao Núcleo Variação Linguística da Região Sul (VARSUL), da Universidade Federal de Santa Catarina (UFSC). Segue o quadro com informações acerca das peças teatrais que foram analisadas:

\footnotetext{
5 O projeto tem como objetivo a formação de um banco de dados para estudo diacrônico, constituído fundamentalmente de peças teatrais escritas por catarinenses nascidos no litoral de Santa Catarina. É coordenado pela Prof $^{a}$ Dr $^{a}$ Izete Lehmukuhl Coelho (UFSC) e tem como colaboradores o Prof. Dr. Marco Antonio Martins (UFRN) e a $\operatorname{Prof}^{\mathrm{a}} \mathrm{Dr}^{\mathrm{a}}$ Isabel de Oliveira e Silva Monguilhot (UFAM/UFSC).
} 


\begin{tabular}{|l|c|l|c|}
\hline \multicolumn{1}{|c|}{ Autor } & $\begin{array}{c}\text { Nascimento e } \\
\text { morte do autor }\end{array}$ & \multicolumn{1}{|c|}{ Peça teatral catarinense } & $\begin{array}{c}\text { Estreia/ } \\
\text { Publicação }\end{array}$ \\
\hline 1. Álvaro Augusto de Carvalho & $1829-1865$ & Raimundo & 1868 \\
\hline 2. José Cândido de Lacerda Coutinho & $1841-1902$ & A casa para alugar & 1867 \\
\hline 3. José Cândido de Lacerda Coutinho & $1842-1902$ & Quem desdenha quer comprar... & 1868 \\
\hline 4. Horácio Nunes Pires & $1855-1919$ & Um cacho de mortes & 1881 \\
\hline 5. Horácio Nunes Pires & $1855-1919$ & Dolores & 1889 \\
\hline 6. Antero dos Reis Dutra & $1855-1911$ & Brinquedos de Cupido & 1898 \\
\hline 7. Ildefonso Juvenal & $1884-1965$ & Hilda, a filha do suposto trahidor & 1942 \\
\hline 8. Ildefonso Juvenal & $1884-1965$ & A filha do Operário & 1947 \\
\hline 9. Ody Fraga & $1927-1987$ & Um homem sem paisagem & 1983 \\
\hline 10. Mário Júlio Amorim & $1939-$ & O dia do javali & 1978 \\
\hline 11. Ademir Rosa & $1950-1997$ & O dia em que os porcos comerão sal & 1992 \\
\hline 12. Ademir Rosa & $1950-1997$ & Os lobos & 1996 \\
\hline 13. Ademir Rosa & $1950-1997$ & O que a vida fez de mim, de nós & 1992 \\
\hline 14. Antônio Cunha & $1961-$ & Flores de Inverno & \\
\hline
\end{tabular}

Quadro 01: Corpus analisado: peças teatrais dos séculos XIX e XX

Os dados coletados estavam inseridos em contextos cujos verbos eram transitivos diretos, para que se pudesse analisar o preenchimento do objeto direto anafórico relacionado a esses verbos. Após a coleta e codificação, os dados foram analisados de acordo com o seguinte envelope de variação:

I - Variável dependente: Objeto anafórico (preenchido ou nulo) em sentenças declarativas.

Variantes: Objeto nulo / objeto preenchido

(7)" [...] Roubou minha pasta!

(8) Pode ter achado cv. Você não disse que perdeu cv? (O dia do javali, 1983)

(9) “ - Hilda esperará. Si ela te ama sinceramente como o afirma a todos, e si ama e estremece a doce Mãe Pátria, dará eloqüente demonstração de patriotismo (...)” ( Hilda, a filha do suposto trahidor, 1918, p. 157)

II - Variáveis Independentes:

1) Época de estreia/publicação da peça teatral;

2) Estatuto da oração: absoluta - principal, coordenada 1, coordenada 2, substantiva, adverbial, adjetiva;

3) Modo - tempo verbal: (i) indicativo: presente, pretérito perfeito, pretérito imperfeito, pretérito mais-que-perfeito, futuro do presente simples, futuro do presente perifrástico, futuro do presente com presente+advérbio, futuro do pretérito; (ii) subjuntivo: presente, pretérito, futuro; (iii) imperativo; 
4) Pessoa do discurso: $1^{\mathrm{a}}, 2^{\mathrm{a}}$ e $3^{\mathrm{a}}$ pessoa;

5) Animacidade do referente: [+ animado], [- animado] 6

6) Especificidade do referente : [+ específico] [- específico]

7) Forma de (não) realização do objeto: nulo, clítico, pronome pleno, demonstrativo (isso, mesmo), $\mathrm{SN}$ simples, $\mathrm{SN}$ oracional.

8) Ordem do objeto : nulo (não se aplica), VO, OV.

9) Elemento(X) entre V e O: não se aplica (VO ou OV), argumento interno (oi), adjuntos, argumento externo.

10) Estatuto do referente: pronome, oração, SN.

11) Estrutura da oração: SVO, SXV, nulo VO e VXO.

Há que se considerar que, se por um lado, eliminamos alguns problemas provenientes da entrevista (constrangimento do informante, sua influência no estilo e o ruído das gravações), por outro, a fala das personagens nos textos teatrais, na verdade, não representa exatamente o vernáculo de pessoas da época, mas sim o estilo do autor das peças. Ou, ainda, os dados linguísticos que encontramos nas peças são fruto do que o autor julga ser, na época, o vernáculo de cada personagem que ele cria. A respeito de situações como essa, Faraco (2005) lembra das palavras de Labov (1994):

Os dados, que são ricos sob muitos aspectos, são pobres sob outros. [...] As formas linguísticas em tais documentos [históricos] são muitas vezes distintas das formas vernáculas dos escritores e, em vez do vernáculo, refletem esforços para capturar uma variedade normativa que nunca foi a língua nativa de nenhum falante. (p. 12 apud Faraco op. cit., p. 124)

Assim, o que talvez tenhamos em nossa pesquisa, na verdade, é o componente linguístico da caracterização da personagem criada pelo autor, segundo suas convenções e intenções. Isso porque, diante das dificuldades enfrentadas pelo pesquisador na área de linguística histórica devido aos dados que muitas vezes não permitem uma investigação mais profunda, cabe ao cientista, nos termos de Labov (op. cit.), "fazer o melhor uso dos maus dados" de que dispõe. Assim, por estarmos cientes de que os dados que teríamos disponíveis não representariam fielmente a fala das personagens de acordo com suas características no contexto em que se inseriam, não consideramos como fatores condicionantes o sexo, a faixa etária e a escolaridade das personagens; antes, levamos em conta a data de estreia/publicação da peça teatral.

No estudo que realizamos, tendo em mente as orientações labovianas para a análise da variação e mudança, primeiramente foi feita a leitura das peças teatrais visando à coleta dos dados que teve como alvo somente as sentenças declarativas com objeto direto anafórico. De posse das ocorrências de objeto direto anafórico encontradas nos textos, os dados foram codificados e analisados com o suporte do programa estatístico VARBRUL ( $c f$. PINTZUK, S, 1988).

Tendo por base a teoria laboviana acerca da variação e mudança e apoiados no programa estatístico VARBRUL (cf. PINTZUK. S., 1988), analisamos as ocorrências de objeto direto anafórico nas quatorze peças teatrais selecionadas. Os resultados obtidos servirão para investigar se estamos ou não diante de um estado de competição entre gramáticas que, de um lado, seguiriam uma construção mais conservadora quanto à exigência de preenchimento do objeto - preferencialmente com clíticos - e, do outro, admitiriam a elipse de objeto anafórico em determinados contextos.

\footnotetext{
${ }^{6}$ Adotei o termo [+ - animado] em vez de [+ - humano] por julgar o primeiro mais abrangente que o segundo.
} 


\section{OS RESULTADOS}

A separação das peças por século e a tentativa de agrupá-las em épocas, de acordo com a data de estreia/ publicação (segunda metade do século XIX, final do século XIX, início do século XX, meados do século XX, segunda metade do século $\mathrm{XX}$ e final do século $\mathrm{XX}$ ), teve por objetivo uma melhor visualização quanto ao período em que se observou a possível mudança quanto à (não)realização do objeto anafórico ou, ainda, o acompanhamento em termos diacrônicos da variação linguística, que foi objeto de nossa pesquisa.

Dentre as onze variáveis independentes que começamos a investigar no início da pesquisa, acabamos por trabalhar com oito, por conta da eliminação de alguns knockouts e dos amálgamas que realizamos quando o número de dados não chegava a ser significativo em relação ao restante da amostra. Além desses, houve também casos em que concluímos, após categorização dos dados, que alguns fatores se sobrepunham a outros ou que não seriam relevantes para este trabalho. Então, acabamos por trabalhar com (i) época de estreia/publicação das peças teatrais, (ii) estatuto da oração, (iii) tempo/modo verbal, (iv) pessoa do discurso, (v) animacidade do referente, (vi) especificidade do referente, (vii) estatuto do referente e (viii) estrutura da oração.

\subsection{O objeto anafórico no português de Florianópolis do século XIX}

Analisamos 358 dados que, após submetidos ao programa estatístico, revelaram os resultados que passamos agora a descrever.

Dos oito grupos de fatores considerados, o programa selecionou, para os dados do século XIX, apenas os seguintes, listados por ordem de relevância e acompanhados por suas hipóteses que levantamos acerca de cada um deles:

$1^{\circ}$ ) Animacidade do referente: [+ animado], [-animado]

(10) - O que foi?

- Eu não sei cv. Eu tive impressão de que já o vi antes. (Flores de Inverno, 1992, p. 4)

Hipótese:

Levando-se em conta os resultados obtidos por Cyrino (2001), esperamos encontrar uma maioria de objetos nulos com antecedente inanimado.

$2^{\circ}$ ) Época de estreia/publicação da peça teatral: $2^{\mathrm{a}}$. Metade do século XIX, final do século XIX, início do século XX, meados do século XX, $2^{\mathrm{a}}$. Metade do século XX e final do século XX.

(11) - Que eu penso, a respeitado Sr. Salustiano, exatametne como minha tia...

[...]

- É porque não o conheces como eu... [...] Tudo quanto diz, sabe dizê-lo tão bem!...(Quem desdenha quer comprar, 1868, p. 20)

(12) [o médico] já cansou de lhe dar remédios mas você não toma cv [...]

- Tome só um gole.

- Não quero cv, pode beber cv você! 
- Agora não quer cv é? ... Só pra me fazer pirraça, tá louco pra tomar cv, eu sei cv, eu sei cv. Vá, eu deixo cv. Beba tudo quanto você quiser cv. (Os Lobos, 1992, p. 15-16)

Hipótese:

Nossa hipótese é que, à medida que se aproxima a segunda metade do século XX, haja maior tendência ao apagamento do objeto (cf. CYRINO, 1990; TARALLO, 1983).

$3^{\circ}$ ) estatuto do referente: pronome, oração, SN.

(13) Não há perigo de morrer de fome... se tiver dinheiro... que há de ter cv... estou convencido de que o tem... se não tiver cv é o mesmo ( A casa para alugar, 1897, p. 53)

(14) - Já veio o Sr. Mendes?

- Não sei cv Snr. (Brinquedos de Cupido, 1898, p. 101)

(15) Eu não chorei. Eu não consegui chorar. Eu não conseguiria cv. (Flores de Inverno, 1992, p. 13)

Hipótese:

Nossa expectativa para o estudo do referente é que, primeiramente, sejam omitidos os objetos que se referirem a orações. Isso porque, entre SNs, pronomes e orações, estas últimas são as que mais provavelmente terão o traço [-animado] e, como Cyrino (2007) já mostrou, antecedentes com esse traço têm maior possibilidade de gerar objetos nulos. Em contrapartida, esperamos que os objetos cujos referentes são SNs e pronomes tenham maior probabilidade de serem preenchidos, pois tendem mais a apresentar o traço [+animado] e [+específico].

\subsubsection{Animacidade do referente}

Após a análise, a animacidade foi o fator apontado como mais significativo pelo programa estatístico Varbrul, conforme atestam os resultados apresentados na tabela a seguir:

\begin{tabular}{cccc}
\hline \multirow{2}{*}{ Animacidade } & \multicolumn{2}{c}{ Objetos nulos } & \multirow{2}{*}{ P.R. } \\
& Número & \% & \\
\hline$[-$ animado $]$ & $57 / 182$ & 31 & .86 \\
\hline$[+$ animado $]$ & $2 / 176$ & 1 & .13 \\
\hline
\end{tabular}

Tabela 7: Frequência e probabilidade de ocorrência de objetos nulos em dados do século XIX, segundo o grupo de fatores animacidade do referente

Os resultados mostraram que o traço [- animado] condiciona favoravelmente a ocorrência de objeto direto anafórico nulo, uma vez que em $31 \%$ dos dados cujos referentes têm traço [- animado] o objeto é elíptico. Por outro lado, houve uma quase unanimidade na opção pelo objeto preenchido nos casos em que o referente é [+ animado]. Cyrino (2007) explica que, com base na Hierarquia da 
Referencialidade, o objeto tende a ser nulo quando o referente é de terceira pessoa e tem o traço [ animado], enquanto que referentes com traço [+ animado] tendem a dar origem a objetos preenchidos.

\subsection{2 Época de estreia/publicação da peça teatral}

O segundo grupo de fatores selecionado como relevante pelo programa estatístico foi a época de estreia/publicação da peça teatral. Apresentamos na tabela que segue os valores que encontramos após a análise:

\begin{tabular}{lcc}
\hline Época de estreia/publicação & Objetos nulos & P.R. \\
\hline Segunda metade do século XIX & $13 \%(26 / 197)$ & .44 \\
\hline Final do século XIX & $20 \%(33 / 161)$ & .57 \\
\hline
\end{tabular}

Tabela 8: Frequência e probabilidade de ocorrência de objetos nulos em dados do século XIX, segundo o grupo de fatores época de estreia/publicação da peça teatral

Observamos, como era de se esperar, que à medida que se aproxima o final do século XIX, há um aumento na tendência ao apagamento do objeto direto anafórico.

Note-se que, apesar de os percentuais não apresentarem uma diferença significativa, os pesos relativos apontam para a probabilidade maior de ocorrências de objetos anafóricos nulos nas peças cuja época de estreia/publicação foi o final do século XIX. Pode-se dizer, ainda, que a tendência, quem sabe, no século seguinte seja o aumento ainda mais significativo nos percentuais de ocorrência de objetos anafóricos nulos na amostra investigada.

Até aqui, portanto, nossa hipótese parece que segue rumo à confirmação de que à medida que se aproxima o século XX, "aproximam-se" também os objetos nulos no português de Florianópolis.

\subsubsection{Estatuto do referente}

O terceiro e último fator selecionado como relevante para o (não) preenchimento do objeto anafórico no PB do século XIX foi o estatuto do referente. Analisamos o estatuto do referente quanto à possibilidade de ser oração ou sintagma nominal.

\begin{tabular}{cccc}
\hline Estatuto do referente & $\begin{array}{c}\text { Objeto nulo } \\
\mathbf{N}^{\circ}\end{array}$ & P. R. \\
\hline Oração & $35 / 89$ & 39 & .74 \\
\hline SN & $24 / 198$ & 12 & .38 \\
\hline
\end{tabular}

Tabela 9: Frequência e probabilidade de ocorrências de objetos nulos em dados do século XIX, segundo o grupo de fatores estatuto do referente

Como mostram os resultados apresentados na tabela, os referentes em forma de oração são 
determinantes do uso do objeto nulo no século XIX, o que confirma nossa hipótese, baseada em Cyrino (2007).

\subsection{Objeto anafórico no português de Florianópolis do século XX}

A exemplo do que ocorreu com os dados do século XIX, o programa também selecionou para ocorrência do objeto anafórico nulo nos dados do século XX os mesmos grupos de fatores e na mesma ordem de relevância:

$\left.1^{\circ}\right)$ animacidade do referente;

$2^{\circ}$ ) época de estreia/publicação da peça teatral e

$3^{\circ}$ ) estatuto do referente.

\subsubsection{Animacidade do referente}

Considerando o traço [+/- animado] do referente, obtivemos os seguintes resultados, que mostramos na tabela que segue:

\begin{tabular}{lccc}
\hline Animacidade & \multicolumn{2}{c}{ Objetos nulos } & P.R. \\
& Número & \% & \\
\hline [- animado $]$ & $139 / 208$ & 67 & .62 \\
\hline [+ animado] & $6 / 48$ & 13 & .10 \\
\hline
\end{tabular}

Tabela 10: Frequência e probabilidade de ocorrência de objetos nulos em dados do século XX, segundo o grupo de fatores animacidade do referente

Percebemos que, no século XX, o fator animacidade é determinante na escolha pela elipse do objeto anafórico, haja vista o elevado percentual e peso relativo associados aos antecedentes com traço [- animado].

\subsection{2 Época de estreia/publicação da peça teatral}

A tabela a seguir mostra os resultados obtidos quando consideramos a época de estreia/publicação da peça teatral: 


\begin{tabular}{llcl}
\hline Época de estreia/publicação & \multicolumn{2}{c}{ Objetos nulos } & P.R. \\
& $\mathbf{N}^{\mathbf{0}}$ & $\mathbf{\%}$ & \\
\hline Início do século XX & $1 / 12$ & 8 & .06 \\
\hline Meados do século XX & $13 / 37$ & 35 & .29 \\
\hline Segunda metade do século XX & $74 / 95$ & 78 & .73 \\
\hline Final do século XX & $57 / 112$ & 51 & .44 \\
\hline
\end{tabular}

Tabela 11: Frequência e probabilidade de ocorrência de objetos nulos no PB do século XX, segundo o grupo de fatores época de estreia/publicação da peça teatral

Observamos, como era de se esperar, que à medida que se aproxima o final do século XX, há aumento na tendência ao apagamento do objeto direto anafórico, com destaque ao "pico" (78\%, P.R $=.73$ ), apresentado na segunda metade do século, e ao certo equilíbrio nos valores correspondentes ao final deste mesmo século.

\subsubsection{Estatuto do referente}

O terceiro e último fator selecionado como relevante para a ocorrência de objetos anafóricos nulos nos dados do século XX coincidiu também com aquele selecionado para os dados do século XIX: o estatuto do referente. Confirma-se, mais uma vez, nossa hipótese formulada a partir de Cyrino (2007), segundo a qual objetos tendem a ser nulos quando têm como referente uma oração:

\begin{tabular}{lccc}
\hline Estatuto do referente & \multicolumn{2}{c}{$\begin{array}{l}\text { Objeto nulo } \\
\mathbf{N}^{\circ}\end{array}$} & P. R. \\
\hline Oração & $79 / 105$ & 75 & .65 \\
\hline SN & $64 / 131$ & 49 & .37 \\
\hline
\end{tabular}

Tabela 12: Frequência e probabilidade de ocorrência de objetos nulos nos dados do século XX, segundo o grupo de fatores estatuto do referente

\subsubsection{O que dizem os resultados do português de Florianópolis?}

A tabela a seguir resume os resultados apontados pelo programa estatístico na análise do (não)preenchimento do objeto anafórico no português de Florianópolis, considerando-se os séculos XIX e XX: 


\begin{tabular}{|c|c|c|c|c|}
\hline \multirow[t]{2}{*}{ Fator selecionado } & \multicolumn{2}{|c|}{ Século XIX } & \multicolumn{2}{|c|}{ Século XX. } \\
\hline & Obj. nulo & P.R. & Obj. nulo & P. R. \\
\hline [+ animado $]$ & $1 \%$ & .13 & $13 \%$ & .10 \\
\hline [- animado] & $31 \%$ & .86 & $67 \%$ & .62 \\
\hline Início do século & - & & $8 \%$ & .06 \\
\hline Meados do século & - & & $35 \%$ & .29 \\
\hline Segunda met. século & $13 \%$ & .44 & $78 \%$ & .73 \\
\hline Final do século & $20 \%$ & .57 & $51 \%$ & .44 \\
\hline Oração & $39 \%$ & .74 & $75 \%$ & .65 \\
\hline $\mathrm{SN}^{\circ}$ & $12 \%$ & .38 & $49 \%$ & .37 \\
\hline
\end{tabular}

Tabela 13: Frequência e probabilidade de ocorrência de objetos nulos, segundo os três grupos de fatores selecionados.

Primeiramente notou-se um aumento de 31 para $67 \%$ nos casos de objeto anafórico nulo cujo referente tem traço [- animado], do século XIX para o século XX. Além disso, o peso relativo (.62) associado ao traço [- animado] do referente confirma a maior probabilidade de ocorrência de objeto nulo nesse caso.

Com o passar dos anos, percebeu-se também que os percentuais de objetos anafóricos nulos aumentaram progressivamente à medida que se aproximou o final do século XX, com destaque para a segunda metade deste século, quando atingiu $78 \%$ dos casos. Também quando o fator considerado foi o estatuto do referente, os percentuais de objetos anafóricos nulos com referentes oracionais foram de $39 \%$ no século XIX, para $75 \%$ no século subsequente.

Não se pode, ainda, deixar de comentar sobre a presença dos clíticos, quando o objeto anafórico é preenchido, sofreu queda acentuada do século XIX para o século XX, como mostra a tabela:

\begin{tabular}{ccc}
\hline Forma de realização & Século XIX & Século XX. \\
\hline Clíticos & $65 \%$ & $30 \%$ \\
\hline Nulos & $12 \%$ & $57 \%$ \\
\hline
\end{tabular}

Tabela 14: Percentual de clíticos e nulos como forma de (não)realização do objeto anafórico nos dados dos séculos XIX e XX.

Tal queda no percentual de clíticos no PB pode estar associada à tendência cada vez maior à elipse do objeto, o que atesta a hipótese de Raposo (2004) para quem, no PB, o objeto nulo resulta da elipse de um clítico ou de um pronome pleno.

Além disso, fatores como animacidade e especificidade do referente mostraram-se importantes nos dois séculos para a (não) realização do objeto: 


\begin{tabular}{lcc}
\hline & Século XIX & Século XX \\
\hline$[-$ animado] & $31 \%$ & $67 \%$ \\
\hline$[+$ animado] & $1 \%$ & $13 \%$ \\
\hline$[-$ específico] & $31 \%$ & $67 \%$ \\
\hline$[+$ específico] & $1 \%$ & $13 \%$ \\
\hline
\end{tabular}

Tabela 15: Percentual de objetos nulos no PB dos séculos XIX e XX segundo os grupos de fatores animacidade e especificidade do referente.

A tabela anterior mostra coincidência entre os percentuais dos objetos nulos cujos referentes têm traço [-animado] e [- específico] e [+animado] e [+ específico] em cada um dos séculos. Além disso, a pesquisa revelou que certos contextos com traço [+animado] e [+ específico] que no século XIX inibiam o uso de objeto nulo, no século XX, começaram a perder sua força, visto que o percentual de elipse nesses casos se elevou de $1 \%$ no século XIX para $13 \%$ no século seguinte.

$\mathrm{O}$ fato de um grupo de fatores se tornar menos rígido quanto à restrição que faz a uma variação ou mudança pode, também, ser mais um indício de que há uma mudança linguística a caminho no PB.

Nota-se, ainda, que os resultados se mostram compatíveis com o que propõe a hierarquia da referencialidade (CYRINO, 2007), uma vez que os percentuais mais altos de elipse do objeto estão relacionados ao traço [-animado] e [- específico] do referente.

Outra questão que merece comentários é que, embora o SN oracional seja favorecedor da omissão do objeto anafórico, percebemos que do século XIX $(12 \%, 24 / 198)$ para o século XX (49\%, 64/131) os objetos cujos referentes são SNs não oracionais também tenderam ao apagamento. Constatamos, nesse caso, a tendência à elipse do objeto, com o passar dos séculos.

No século XX, os objetos nulos com antecedente não oracional chegaram a quase metade do percentual dos casos analisados, enquanto no século XIX eram apenas 12\%. Mais uma vez, constatou-se que cada vez mais se elevam os percentuais de elipse quando se consideram aqueles fatores que, no século XIX, inibiam a mudança.

Os resultados atestam, enfim, que estamos vivenciando no português de Florianópolis uma tendência cada vez maior à elipse do complemento verbal anafórico, favorecida principalmente pela passagem dos anos, pelo traço [- animado] do referente e pelo estatuto do elemento a que se refere o objeto.

Em todos os casos alia-se um fator de ordem semântico-pragmática (animacidade), um de ordem sintática (estatuto do referente) e um de ordem extralinguística (época de estreia/publicação da peça teatral).

Além disso, em se tratando do traço animacidade do referente, constatou-se que ele representa o fator que mais influencia na opção pela elipse do complemento verbal, o que comprova para os dados de de Florianópolis o que alguns estudos já atestaram em relação a outros corpora (cf. CYRINO, 2007).

No século XIX, vimos que em $31 \%$ dos caso em que o referente era [- animado] e [específico] o objeto era nulo e, no século XX esses valores passaram para $67 \%$.

O que se pode perceber, portanto, é um aumento em relação ao século XIX nos percentuais de objetos nulos apresentados no século XX , sendo que há um grande salto (mais que o dobro) 
entre os dois séculos no percentual de objetos nulos com antecedente [- animado] e [- específico].

Desse modo, é possível constatar que há, sim, como afirma Cyrino (2007) relação entre a hierarquia da referencialidade e a opção pela elipse do objeto no PB.

A época de estreia/publicação da peça, segundo fator selecionado para o PB, também comprovou nossa hipótese de que à medida que se aproximam os dias atuais, cresce a possibilidade de ocorrerem objetos anafóricos nulos.

A seleção do estatuto do referente - terceiro fator selecionado - mostrou que o percentual de uso de objetos diretos anafóricos nulos comprovou os resultados revelados em outras pesquisas, como a de Cyrino (2007): os referentes oracionais tendem mais a gerar objetos nulos que os referentes em forma de SN. Quando o referente é um SN não oracional, observamos um "salto" do século XIX para o século XX bem maior nos percentuais:

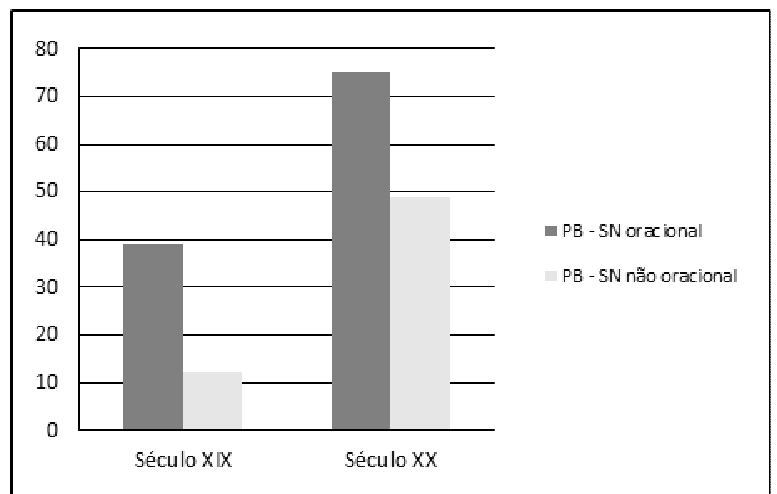

Gráfico 01: Percentuais de objetos nulos no PB com antecedentes oracionais e SNs não oracionais

Para melhor visualizarmos o fenômeno do preenchimento do objeto anafórico no PB de Florianópolis, pusemos todos os percentuais obtidos para cada grupo de fatores no quadro a seguir:

\begin{tabular}{|l|lc|}
\hline $\begin{array}{l}\text { Grupos de Fatores } \\
\text { selecionados }\end{array}$ & Século XIX & Século XX \\
\hline [+ animado] & $1 \%$ & $13 \%$ \\
[- animado] & $31 \%$ & $67 \%$ \\
Início do século & - & $8 \%$ \\
Meados do século & - & $35 \%$ \\
2 $^{\text {a met. do século }}$ & $13 \%$ & $78 \%$ \\
Final do século & $20 \%$ & $51 \%$ \\
Oração & $39 \%$ & $75 \%$ \\
SN & $12 \%$ & $49 \%$ \\
Clíticos & $65 \%$ & $30 \%$ \\
Nulos & $12 \%$ & $57 \%$ \\
& & \\
\hline
\end{tabular}

Quadro 02: preenchimento do objeto dos séculos XIX e XX, segundo todos os fatores selecionados 
O primeiro resultado para o qual o quadro chama nossa atenção diz respeito ao estatuto do referente, se SN ou oração. Percebemos que houve um aumento de quase $100 \%$ no percentual de elipse do objeto quando o referente era uma oração. Quando voltamos o olhar para os objetos nulos cujos referentes são SNs, percebe-se também uma diferença grande (de 37\%).

Percebeu-se, no quadro, levando-se em consideração a animacidade do referente nos dados, o aumento do percentual de ocorrência de objetos nulos que sobe de $31 \%$ no século XIX para $67 \%$ no século XX. O estatuto do referente também se consolidou na pesquisa como favorecedor na opção pela elipse do objeto, revelando percentual que subiu de $39 \%$ no século XIX para $75 \%$ no século seguinte.

Por fim, os percentuais apontaram para uma queda bastante acentuada - de $65 \%$ para $30 \%$ na frequência de clíticos português de Florianópolis do século XIX para o XX, aliada ao aumento expressivo - de $12 \%$ para $57 \%$ - da elipse do objeto. O que podemos afirmar diante de tais percentuais é que parece realmente haver uma relação entre a realização do objeto anafórico e o uso de clíticos.

É chegado, então, o momento de retomarmos algumas hipóteses que levantamos ao longo deste trabalho para, à luz dos resultados obtidos, verificarmos quais foram confirmadas ou não.

Propusemo-nos, também, a investigar a respeito dos fatores [animacidade] e [especificidade], apontados, entre outros por Cyrino (2007), como determinantes na opção pela elipse do complemento verbal. Como foi possível constatar com a análise dos resultados que acabamos de apresentar, esses fatores quanto ao seu traço negativo se mostraram, sim, favorecedores do uso de objetos nulos.

Como já apontado anteriormente, os resultados que dizem respeito ao uso dos clíticos podem sinalizar uma relação, entre a queda dos clíticos e o uso cada vez maior de objetos nulos. Lembremo-nos de que o percentual de nulos no século XIX era de apenas $12 \%$, subindo para $57 \%$ no século XX.

Em se tratando do grupo de fatores época de estreia/publicação da peça teatral, temos comentários importantes para tecer. Embora não tenha sido o primeiro fator selecionado em cada uma das etapas de nossa pesquisa, ele estava presente em todas. Percebemos que a chegada do século XX veio acompanhada de um aumento no percentual de objetos nulos e, também, se considerarmos os pesos relativos associados aos grupos de fatores, veremos que a passagem do século XIX para o XX reafirmou a probabilidade de uso de objetos nulos em relação a cada fator selecionado. Pode-se dizer, então, que estamos caminhando, em termos de preenchimento de complemento do verbo para uma mudança em tempo real.

Em termos labovianos, nossa análise revelou que há alguns grupos de fatores cujo papel é, ainda, restringir o uso de objetos nulos, favorecendo o preenchimento do objeto. Constatamos que as orações coordenadas 1, substantivas e adjetivas favorecem o preenchimento do objeto anafórico. Em especial, destacamos as últimas, para as quais o programa revelou $100 \%$ de preenchimento do objeto.

Além desse, o tempo verbal mais-que-perfeito mostrou-se favorecedor de objetos preenchidos; também o tempo futuro (do pretérito e do presente) mostrou-se não muito favorável à elipse do objeto. Contextos em que o referente do objeto era a $1^{a}$ pessoa do singular ou a $1^{\mathrm{a}}$ ou $2^{\mathrm{a}}$ pessoa do plural também se mostraram determinantes para o preenchimento e, portanto, inibidoras da elipse de objeto, que ficou mais favorecida nos casos de referentes de terceira pessoa.

Em contrapartida, o traço semântico (animacidade / especificidade) e o estatuto do referente (nulo de oração ou nulo de $\mathrm{SN}$ ), revelaram-se como os contextos mais importantes quanto ao favorecimento à elipse do objeto.

Observou-se que a diferença nos percentuais de aumento de objeto nulo com referente oracional e com referente SN não oracional é praticamente a mesma (em torno de 36\%) do século 
XIX para o século XX. Tal fato parece significativo para nossa análise na medida em que aponta para um aumento na opção pela elipse do objeto relacionada a referentes não oracionais.

Ainda, refletindo sobre o problema do encaixamento linguístico e levando em conta nosso objeto de estudo, observamos o que ocorreu com os percentuais de clíticos e de ocorrência de objetos nulos nos séculos XIX e XX, apresentados no Quadro 2: quanto maior o percentual de clíticos no século XIX, menor o percentual de objetos nulos e, quanto maior o percentual de objetos nulos no século XX, menor é o percentual de clíticos.

Outro problema empírico que Weinreich, Labov e Herzog (1968) discutem e do qual nos propusemos a tratar é a transição. O que nos parece, com relação ao objeto que estudamos é que, como ainda convivemos com dois sistemas (um que licencia objetos nulos e outro que o preenche) estamos, quem sabe, a caminho de uma mudança. Observamos, ao longo da pesquisa, que as duas formas (objeto nulo e preenchido) estão convivendo sem que haja muitas restrições entre o uso de uma ou outra.

Talvez possamos ainda dizer que estamos próximos do momento da implementação da mudança, tendo em vista o grande salto nos percentuais de objeto nulo apresentados do século XIX para o século XX.

Além dos problemas empíricos de Weinreich, Labov e Herzog (1968), nosso trabalho também se pautou na teoria de Kroch $(1989 ; 1994 ; 2001)$. Kroch defende que existe relação entre a mudança linguística e o estágio que ele nomeia gramáticas em competição.

Com base na teoria de Kroch que entende a mudança como resultado do processo em que certas estruturas gramaticais acabam por se substituírem após terem convivido por certo tempo, podemos afirmar que, no caso da (não)realização do objeto anafórico na língua portuguesa estamos diante de um período de covariação no PB entre uma gramática de objetos nulos e outra, que ainda preenche objeto anafórico em certos contextos, como mostra o gráfico a seguir, em que representamos os percentuais gerais de objetos nulos no português de Florianópolis:

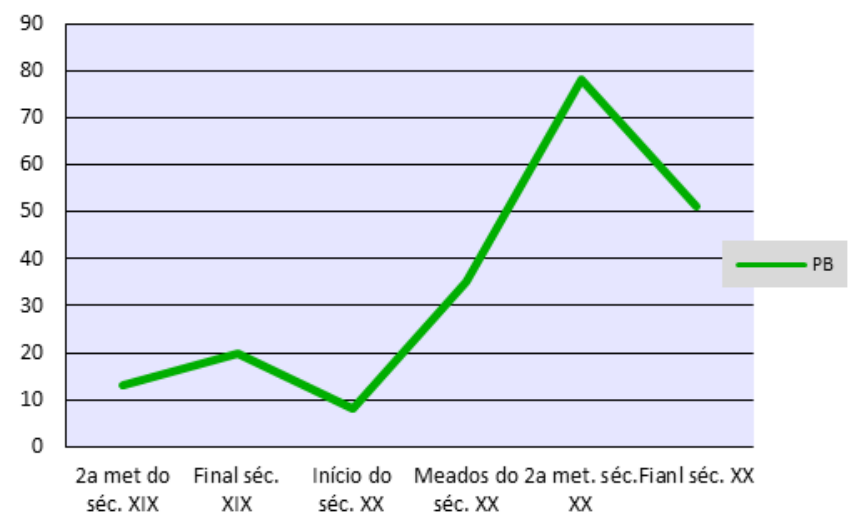

Gráfico 02: Objeto nulo, no português de Florianópolis, em diferentes épocas

Buscamos mostrar de que modo o uso do objeto nulo aconteceu nos diferentes momentos da história, distribuídos no século XIX e XX, a exemplo do que fez Kroch (1989) com o uso do auxiliar do do inglês, estudado por Ellegard.

Assim como o que ocorreu no gráfico de Kroch (1989), nossos resultados também culminaram em curvas cuja inclinação parece mostrar que o português florianopolitano segue rumo à implantação do objeto anafórico elíptico, principalmente até a metade do século XX. Entretanto, se analisarmos os gráficos 03 e 04, a seguir, perceberemos que, na verdade, o PB apresenta algo de 
novo na passagem do século XIX para o século XX: o percentual de objetos anafóricos nulos cresce consideravelmente, indicando que são cada vez mais resultado, entre outros, de referentes SNs não oracionais.

Examinemos os gráficos 03 e 04 que representam, respectivamente, o percentual de objetos nulos anafóricos com referente SN não oracional e oracional:

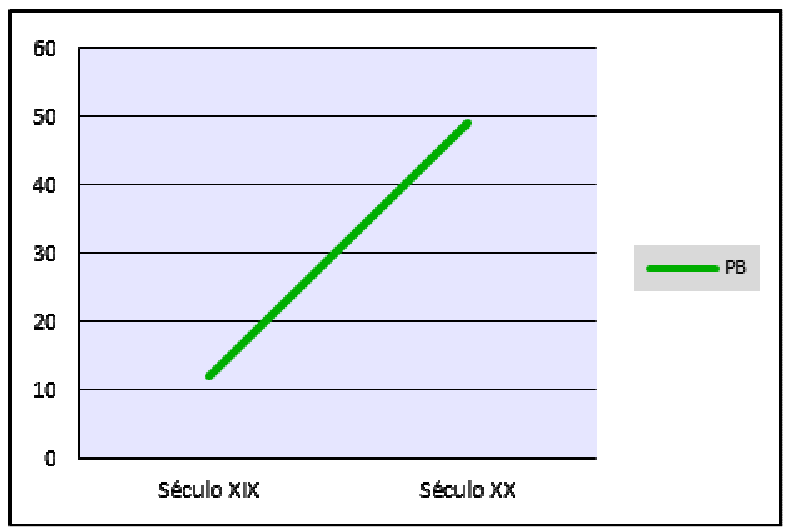

Gráfico 03: Percentual de objetos nulos, por século, com referente SN não oracional no português de Florianópolis

No gráfico 03 fica nítida a influência de referentes SN não oracionais em dados do século XX em relação ao século XIX. A curva representada no gráfico mostra que o século XX é marcado por SNs não oracionais que originam estruturas com objeto anafórico nulo.

Vejamos agora, o que nos diz o gráfico 04:

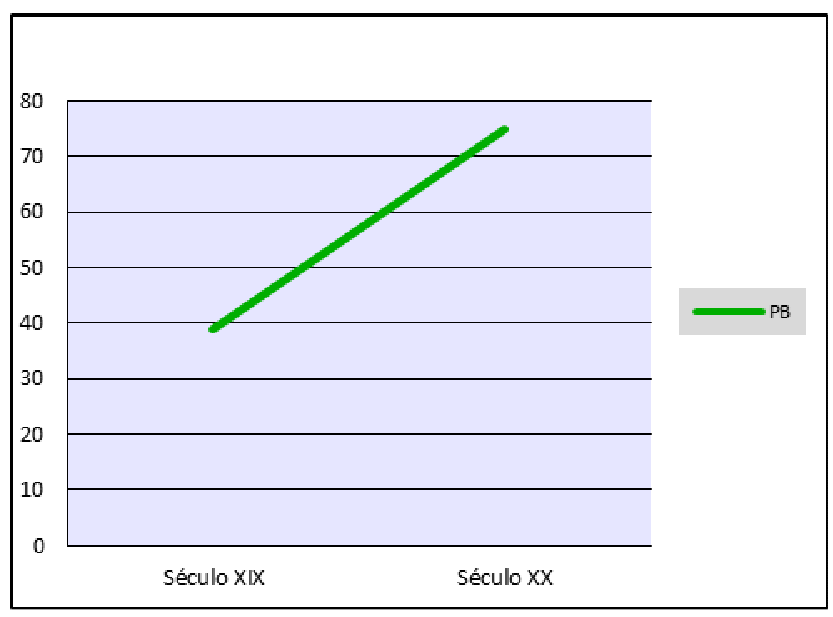

Gráfico 04: Percentual de objetos nulos, por século, com referente oracional no português de Florianópolis

O gráfico 04, por sua vez, apresenta um alto percentual (75\%) de objetos nulos no século $\mathrm{XX}$, acompanhando, de certa forma, a tendência ao preenchimento que era observada no século anterior. 


\section{CONSIDERAÇÕES FINAIS}

Após a análise diacrônica feita em torno dos dados de objeto direto anafórico oriundos de peças teatrais do português florianopolitano, é o momento de tecermos alguns comentários sobre nossa pesquisa.

Diante dos resultados que apresentamos, cabe-nos, ainda, refletir um pouco sobre o papel da escola no ensino dos complementos verbais. Vimos que, de forma geral, as gramáticas tradicionais não fazem referência ao objeto anafórico e nem sequer mencionam o fato de que o objeto pode estar, em alguns casos, elíptico na oração. Acabam, com isso, apenas "mostrando" aos alunos que existem alguns verbos chamados transitivos que precisam de complemento para serem compreendidos na frase, sem que proporcionem aos alunos o momento para refletir sobre a língua que utilizam no dia a dia. Quando discutimos em sala de aula, é preciso que consideremos a variação a que a língua está sujeita e, mais ainda, em se tratando de preenchimento de objeto, que consideremos que há muitas situações em que é possível, sim, optarmos pelo preenchimento ou não do objeto no PB.

Vimos também que o assunto de que tratamos aqui está longe de ser esgotado, que outros estudos diacrônicos ou sincrônicos ainda estão por se realizarem e que a utilização de diferentes corpora de outras partes do Brasil e do mundo servirão para ajudar a mapear como o objeto anafórico está (ou não) sendo preenchido nas mais diversas regiões brasileiras.

\section{REFERÊNCIAS}

BECHARA, Evanildo (1974). Moderna gramática portuguesa. São Paulo: Companhia Editora Nacional.

CEGALLA, Domingos Paschoal (1984). Novíssima gramática da língua portuguesa. São Paulo: Companhia Editora Nacional.

CYRINO, Sonia Maria Lazzarini (1993). "Observações sobre a mudança diacrônica no português do Brasil: objeto nulo e clíticos". In: ROBERTS, Ian \& KATO, Mary A. (orgs.) Português brasileiro: uma viagem diacrônica. Campinas/SP: Editora da Unicamp.

. (1997). O objeto nulo no português do Brasil. Londrina: Editora da UEL.

(2007). Objeto nulo nas cartas de leitores publicadas na imprensa brasileira do século XIX. In: RAMOS, Jânia M.; ALCKMIN, Mônica A (orgs). Para a história do português brasileiro. Belo Horizonte: Faculdade de Letras da UFMG.

.(2001). "O objeto nulo no português do Brasil e no português de Portugal". Boletim da ABRALIN n’ 25 173-181.

(2003). Para a história do Português Brasileiro: a presença do objeto nulo e a ausência dos clíticos. In: Letras de Hoje v. 38 nº 1, p. 31-47, Porto Alegre.

(2007). Mudança sintática e português brasileiro. In: CASTILHO, Ataliba et al.(org.). Descrição, história e aquisição do português brasileiro. Campinas: Pontes, p. 361-373, 2007b.

CUNHA, Celso; CYNTRA, Lindley (1996). Nova gramática do português contemporâneo. Lisboa: Edições João Sá da Costa. 12 ed.

DUARTE, Maria Eugênia Lamoglia (1986). Variação e sintaxe: clítico acusativo, pronome lexical e categoria vazia no português do Brasil. Dissertação de Mestrado. PUC - SP.

Work. Pap. Linguíst., 15(2): 116-139, Florianópolis, ago/dez, 2014 
FARACO, Carlos Emílio; MOURA, Francisco Marto de (1987). Gramática. São Paulo: Ed. Ática. KATO, CYRINO \& CORREA (1995). The recovery of diachronic losses through schooling. Paper presented at the NWAVE, U PENN.

KROCH, Anthony (1978). Toward a theory of social dialect variation. Language in society. Volume7. Cambridge University Press.

(1989). Reflexes of grammar in patterns of language change. Language Variations and change, 1: 199- 244.

(1994). Morphosyntactic variation. In: K. Beals et al (eds.), Papers from the $30^{\text {th }}$ regional meeting of the Chicago Language society, Vol 2: The Parassession on Variation in linguistic theory.

(2001). Syntactic Change. In: Baltin \& Collins (eds) The handbook of contemporary syntactic theory. Massachussetts. USA: Blackwell. 2001, p. 699-729.

LABOV, William (1972). Sociolinguistics Patterns. Philadelphia, University of Pennsylvania Press.

.(1978). "Where does the linguistic variable stop? A response to Beatriz Lavandera" Working Papers in Sociolinguistics. Austin, Texas, n. 44, abril.

.(1982). "Building on Empirical Foundations". In. Winfred P. Lehmann \& Yakov Malkiel (eds) Perspectives on Historical Linguistics. Amsterdam/Philadelphia: John Benjamins. p. 19-92.

.(1994). The functional character of change. In: Language and society 20. Principles of linguistic change - internal factors. Cambridge, Blackwell, p. 545-605.

MACAMBIRA, José Rebouças (1987). A estrutura morfo-sintática do português. São Paulo: Pioneira.

MARTINS, Marco Antonio (2009). Competição de gramáticas do português na escrita catarinense. Florianópolis: UFSC, Tese de doutorado.

MATTOS E SILVA, Rosa Virgínia (1989). Tradição gramatical e gramática tradicional. São Paulo: Contexto.

OMENA, Nelize Pires (1978). Pronome pessoal de terceira pessoa: suas formas variantes em função acusativa. Dissertação de mestrado. Rio de Janeiro: Pontifícia Universidade Católica do Rio de Janeiro.

PASCHOALIN \& SPADOTO (1996). Gramática . São Paulo: FTD.

PERINI Mário A (1995). Gramática descritiva do português. São Paulo: Ática.

PINTZUK, S.V. (1988) Programs. Mimeo.

RAPOSO, Eduardo P. (2004). Objetos nulos e CLLD: uma teoria unificada. In.: Revista da ABRALIN, v.3, Brasília-DF, p. 41-73.

TARALLO, Fernando (1983). Relativization strategies in Brazilian portuguese. Universidade da Pensilvânia. Tese de doutorado.

WEINREICH, Uriel; LABOV, William; HERZOG, Marvin (1968). Fundamentos empíricos para uma teoria de mudança lingüística.(1968) BAGNO, Marcos (trad.) São Paulo: Parábola, 2006

\section{PEÇAS TEATRAIS}


AMORIM, Mário Júlio (1983). O dia do Javali . Texto não publicado. Manuscrito do autor cedido por Antônio Cunha.

CARVALHO, Álvaro Augusto de. [1868] Raimundo - drama em cinco atos. Florianópolis: FCC, ed. da UFSC, 1994.

COUTINHO, José Cândido de Lacerda. [1867] Quem desdenha quer comprar: comédia em um ato/A casa para alugar: comédia em um ato. Porto Alegre: Movimento, 2001.

CUNHA, Antônio. [1992] Flores de Inverno. Três d(r)amas possíveis. Joinville: Letradágua, 2004, p. 82-111. Peça em um ato.

DUTRA, Antero dos Reis Dutra. Brinquedos de Cupido (1898) In.: Miscellanea. Desterro. Drama de um ato.

FRAGA, Ody. [1954] . Um homem sem paisagem [1947] . In.: SUL - Revista de Arte Moderna, ano $1, n^{\circ} 5$. Florianópolis, agosto de 1948.

JUVENAL, Idelfonso. A filha do operário (1942). Obras Completas - Teatro. Volume I. Florianópolis, 1942, p.74-121.

Hilda, a filha do suposto trahidor (1918). Obras Completas - Teatro. Volume I. Florianópolis, 1942, p.74-121.

NUNES, Horácio. [1881] Um cacho de mortes. In: JUNKES, Lauro (org.) Teatro Selecionado. Florianópolis: FCC, ed. da UFSC, 1999, p.197-216.

.[1889] Dolores. In: JUNKES, Lauro (org.) Teatro Selecionado. Florianópolis: FCC, ed. da UFSC, 1999, p. 134-196.

ROSA, Ademir. O dia em que os Porcos Comerão Sal (1978). In.: UCZAI, Pedro (org.) Ademir Rosa: paixão pela arte, paixão pela vida. Florianópolis: [s.n.], 2007, p. 223-258. Peça de um ato.

Os Lobos [1992]. In.: UCZAI, Pedro (org.) Ademir Rosa: paixão pela arte, paixão pela vida.Florianópolis: [s.n.], 2007, p. 195-219. Consulta ao texto manuscrito de Ademir Rosa cedido por Antônio Cunha. Peça em um ato.

O que a vida fez de mim, de nós (1996) In.: UCZAI, Pedro (org.) Ademir Rosa: paixão pela arte, paixão pela vida. Florianópolis: [s.n.], 2007, p. 289-323.

Data de submissão: 14/05/2014

Data de aceite: 24/04/2015 